\title{
Catalysis of iron core formation in Pyrococcus furiosus ferritin
}

\author{
Kourosh Honarmand Ebrahimi · Peter-Leon Hagedoorn • \\ Jaap A. Jongejan · Wilfred R. Hagen
}

Received: 18 March 2009/ Accepted: 9 July 2009/Published online: 22 July 2009

(c) The Author(s) 2009. This article is published with open access at Springerlink.com

\begin{abstract}
The hollow sphere-shaped 24-meric ferritin can store large amounts of iron as a ferrihydrite-like mineral core. In all subunits of homomeric ferritins and in catalytically active subunits of heteromeric ferritins a diiron binding site is found that is commonly addressed as the ferroxidase center (FC). The FC is involved in the catalytic $\mathrm{Fe}(\mathrm{II})$ oxidation by the protein; however, structural differences among different ferritins may be linked to different mechanisms of iron oxidation. Non-heme ferritins are generally believed to operate by the so-called substrate FC model in which the FC cycles by filling with $\mathrm{Fe}(\mathrm{II})$, oxidizing the iron, and donating labile $\mathrm{Fe}(\mathrm{III})-\mathrm{O}-\mathrm{Fe}(\mathrm{III})$ units to the cavity. In contrast, the heme-containing bacterial ferritin from Escherichia coli has been proposed to carry a stable FC that indirectly catalyzes Fe(II) oxidation by electron transfer from a core that oxidizes Fe(II). Here, we put forth yet another mechanism for the non-heme archaeal 24-meric ferritin from Pyrococcus furiosus in which a stable iron-containing FC acts as a catalytic center for the oxidation of $\mathrm{Fe}(\mathrm{II})$, which is subsequently transferred to a core that is not involved in $\mathrm{Fe}(\mathrm{II})$-oxidation catalysis. The proposal is based on optical spectroscopy and steady-state kinetic measurements of iron oxidation and dioxygen consumption by apoferritin and by ferritin
\end{abstract}

Electronic supplementary material The online version of this article (doi:10.1007/s00775-009-0571-z) contains supplementary material, which is available to authorized users.

K. Honarmand Ebrahimi · P.-L. Hagedoorn ·

J. A. Jongejan · W. R. Hagen $(\bowtie)$

Department of Biotechnology,

Delft University of Technology,

Julianalaan 67 ,

2628 BC Delft,

The Netherlands

e-mail: w.r.hagen@tudelft.nl preloaded with different amounts of iron. Oxidation of the first $48 \mathrm{Fe}$ (II) added to apoferritin is spectrally and kinetically different from subsequent iron oxidation and this is interpreted to reflect FC building followed by FC-catalyzed core formation.

Keywords Ferritin - Ferroxidase - Kinetics · Pyrococcus furiosus · UV-vis spectroscopy
Abbreviations
EcBFR Escherichia coli bacterioferritin
EcFtnA Escherichia coli ferritin A
FC Ferroxidase center
MOPS 3-(N-Morpholino)propanesulfonic acid
PfFtn Pyrococcus furiosus ferritin
Tris Tris(hydroxymethyl)aminomethane

\section{Introduction}

Ferritin is a conserved protein that can be found in many forms of life, e.g., animals, plants, and microorganisms [1-4]. The function of ferritin appears to be essential since, e.g., deletion of its gene leads to apoptosis and death in mice embryonic cells [5]. Its quaternary structure consists of 24 subunits that assemble into a hollow spherical shape with octahedral (4-3-2) symmetry and with an outer and an inner diameter of 12 and $8 \mathrm{~nm}$, respectively.

In mammals, ferritin consists of two subunits, $\mathrm{H}$ ("heavy") and L ("light") chains with molecular masses of approximately 21 and $19 \mathrm{kDa}$, respectively. It has been suggested that $\mathrm{L}$ subunits are catalytically inactive since no diiron nuclear center has been found in their structure, whereas $\mathrm{H}$ 
subunits are catalytically active and directly involved in the iron oxidation process [6, 7]. In amphibian red cells, three types of subunits $(\mathrm{H}, \mathrm{M}$, and $\mathrm{L})$ form hetropolymeric ferritins [8]. It appears that $M$ subunits have functional properties similar to those of $\mathrm{H}$ subunits. In bacterial, archaeal, and plant ferritins, all 24 subunits are identical.

The ferritin of the hyperthermophilic archaeal anaerobe Pyrococcus furiosus (PfFtn) has 24 identical subunits, and each subunit has a diiron ferroxidase center (FC). The structure of the FC of PfFtn, based on crystallographic studies [9], is outlined in Fig. 1 including a third iron: site C. The third iron site has been found in other ferritin proteins, including Archaeoglobus fulgidus ferritin [10] and Escherichia coli ferritin A (EcFtnA) [11, 12].

It is generally believed that the FC is a so-called substrate active site, where iron is oxidized and released into the cavity to form a core [3,13-23], and is thus functionally different from the catalytic diiron center of a similar structure found in oxygenases and in ribonucleotide reductase [24]. However, Baaghil et al. [25] have suggested that in E. coli bacterioferritin (EcBFR) $\mathrm{Fe}^{3+}$ in the $\mathrm{FC}$ is a stable cofactor over the time course of catalysis and acquires electrons from a core that has catalytic activity. This proposal has very recently found support in a structural study of EcBFR, in which also a novel $\mathrm{Fe}^{2+}$ binding site (named " $\mathrm{Fe}^{2+}$ internal") was identified and proposed

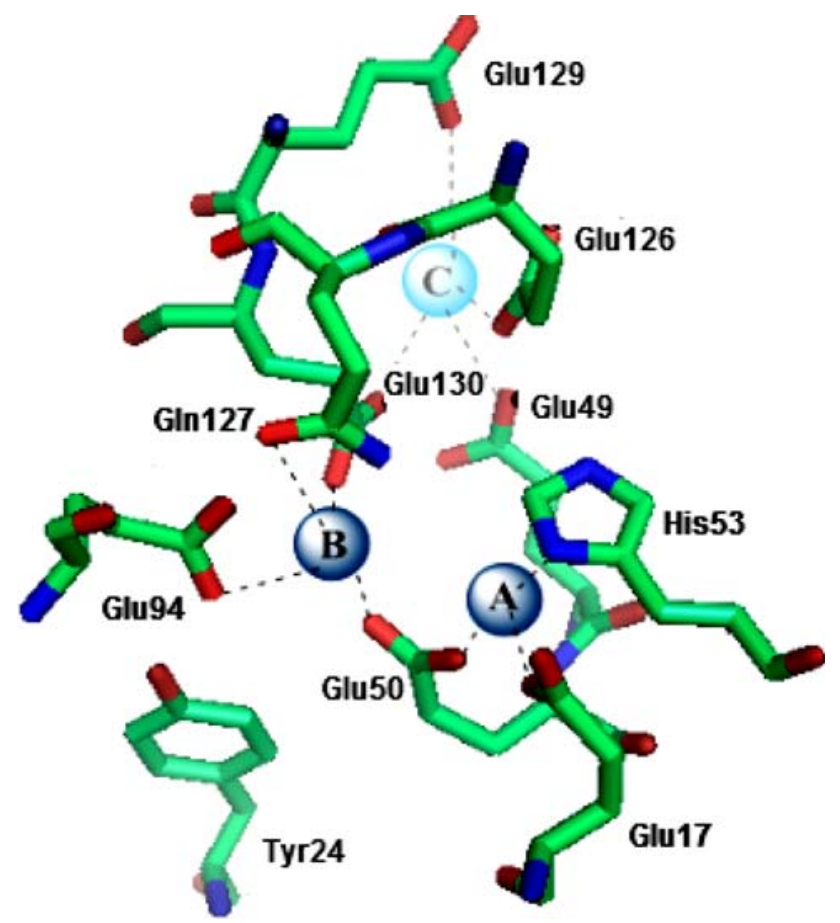

Fig. 1 The ferroxidase center of Pyrococcus furiosus ferritin including a third iron site, site $\mathrm{C}$. Site $\mathrm{C}$ is located inside the protein shell. The figure was prepared with PyMOL and ChemDraw using coordinates from iron-soaked crystals [Protein Data Bank (PDB) entry 2jd7] [8] to act in electron transfer from the core to the FC [26]. Furthermore, Tatur and Hagen [27] found that the FC in PfFtn is a stable prosthetic group in reversible redox titrations.

On the basis of the substrate active site model, three main reactions have been proposed for the in vitro iron mineralization process by ferritin with dioxygen as an oxidant (reactions 1-3) [22, 23, 28-30].

$2 \mathrm{Fe}^{2+}+\mathrm{O}_{2}+4 \mathrm{H}_{2} \mathrm{O} \rightarrow 2 \mathrm{FeOOH}_{(\text {core })}+4 \mathrm{H}^{+}+\mathrm{H}_{2} \mathrm{O}_{2}$

$2 \mathrm{Fe}^{2+}+\mathrm{H}_{2} \mathrm{O}_{2}+2 \mathrm{H}_{2} \mathrm{O} \rightarrow 2 \mathrm{FeOOH}_{(\text {core })}+4 \mathrm{H}^{+}$

$4 \mathrm{Fe}^{2+}+\mathrm{O}_{2}+6 \mathrm{H}_{2} \mathrm{O} \rightarrow 4 \mathrm{FeOOH}_{(\text {core })}+8 \mathrm{H}^{+}$

It has been suggested that reaction 1 occurs in the FC, where two ferrous ions are oxidized and released to the core, and that it occurs at all $\mathrm{Fe}^{2+}$ to ferritin ratios. In the second reaction, ferrous ions are oxidized by hydrogen peroxide that is produced in the first reaction. Reaction 2 occurs for intermediate levels of iron loading. The third reaction has been proposed to be dominant when $\mathrm{Fe}^{2+}$ is added to apoferritin in ratios higher than $200 \mathrm{Fe}^{2+}$ per ferritin in one step. It has been hypothesized that at high $\mathrm{Fe}^{2+}$ to ferritin ratios a core is formed which itself contributes to the oxidation of iron with a stoichiometry of four $\mathrm{Fe}^{2+}$ ions per oxygen molecule.

In the present work we used a combination of UV-vis spectroscopy and oxygen uptake measurements to study the PfFtn iron mineralization process and the functioning of the FC. Recombinant PfFtn has some practical added value as a model protein for studying the in vitro iron mineralization process: it is extremely stable [no significant loss of $\mathrm{Fe}^{2+}$-oxidation activity is observed after $10 \mathrm{~h}$ boiling at $100{ }^{\circ} \mathrm{C}$ ] and it is highly overexpressed heterologously ( $25 \%$ of soluble protein in E. coli), leading to an easy purification procedure [31]. The 24-mer is homomeric, and its X-ray structure has been determined [9].

\section{Materials and methods}

\section{Chemicals}

All chemicals were purchased from Sigma-Aldrich. and were reagent grade. Bovine liver catalase $\left(19,900 \mathrm{U} \mathrm{mg}^{-1}\right)$ was also obtained from Sigma-Aldrich.

Protein, expression, and purification

Escherichia coli cells that contain the structural gene of PfFtn in vector pET24a(+) [31] were used. Cells were grown using terrific broth medium at $37^{\circ} \mathrm{C}$ and $200 \mathrm{rpm}$. 
After $2 \mathrm{~h}$, production of PfFtn was induced by addition of $1 \mathrm{mM}$ isopropyl $\beta$-D-thiogalactopyranoside. Eight hours after induction, cells were harvested using centrifugation, resuspended in $10 \mathrm{mM}$ tris(hydroxymethyl)aminomethane (Tris) buffer, $\mathrm{pH}$ 8, and broken using a cell disrupter (Constant Systems), operating at a pressure of $1.3 \mathrm{kbar}$, followed by one-step centrifugation to obtain a cell-free extract as the supernatant, which was subjected to boiling at $100{ }^{\circ} \mathrm{C}$ for $20 \mathrm{~min}$. PfFtn was obtained after centrifugation and removal of the pellet containing denatured E. coli proteins. Purified protein was concentrated to $10 \mathrm{ml}$ and extensively washed by sequential dilution and concentration steps with a total of 11 of $10 \mathrm{mM}$ Tris buffer.

\section{Apoferritin preparation}

Apoferritin was prepared using the method of Bauminger et al. [32] and Dawson et al. [33] under strict anaerobic conditions using an overpressure of 5.0-quality nitrogen gas. PfFtn was washed with $10 \mathrm{mM}$ dithionite in Tris buffer using a 50-ml Amicon cell concentrator system with a $30-\mathrm{kDa}$ filter (Millipore). Finally, the protein solution was incubated with sodium dithionite overnight at $4{ }^{\circ} \mathrm{C}$. Free $\mathrm{Fe}^{2+}$ ions were then chelated using $2 \mathrm{ml}$ of $0.5 \mathrm{M}$ anaerobic solution of $2,2^{\prime}$-bipyridyl, followed by extensive dialysis against working buffer. The buffer was changed to $100 \mathrm{mM}$ 3-( $N$-morpholino)propanesulfonic acid (MOPS), $\mathrm{pH}$ 7. The protein concentration was determined with the bicinchoninic acid assay reagent (Pierce) using bovine serum albumin as a standard.

\section{Determination of iron content}

The iron content of apoferritin was determined colorimetrically at $593 \mathrm{~nm}$ as the ferene complex using an Ultraspec 2100 pro spectrophotometer (GE Healthcare) as described previously [34]. Apoferritin contained less than one iron per ferritin (24-mer).

\section{Initial-rate measurements}

The steady-state kinetics of iron mineralization was followed using a fiber-optics spectrophotometer (Avantes). Initial rates were measured at different wavelengths; however, the results for the iron mineralization kinetics are reported at $315 \mathrm{~nm}$ unless otherwise mentioned. Spectra were recorded from approximately $5 \mathrm{~s}$ after the addition of an anaerobic solution of ferrous sulfate. Kinetic measurements were carried out in $100 \mathrm{mM}$ MOPS, $\mathrm{pH} 7.0$, using $1-\mathrm{ml}$ glass cuvettes with a path length of $1 \mathrm{~cm}$. The specific activity (defined as micromoles of $\mathrm{Fe}^{3+}$ formed per minute per milligram of 24-meric ferritin) was determined from the initial rate measured at $315 \mathrm{~nm}$ using an extinction coefficient of $2.5 \mathrm{mM}^{-1} \mathrm{~cm}^{-1}$.

Preparation of $\mathrm{Fe}^{2+}$ solutions

A solution of distilled water/HCl, $\mathrm{pH} 1.25$, was made anaerobic using wetted argon gas. This solution was added to the ferrous sulfate in an anaerobic glove box (less than $3 \mathrm{ppm}$ $\mathrm{O}_{2}$, Coy Laboratory Products). For each titration the appropriate amount of ferrous sulfate $(1-10 \mu \mathrm{l})$ was added to the protein solution to reach an appropriate $\mathrm{Fe}^{2+}$ to ferritin ratio.

Oxygen-consumption measurements

Oxygen consumption was measured in $100 \mathrm{mM}$ MOPS buffer, pH 7.0, at ambient temperature (about $22^{\circ} \mathrm{C}$ ) using a Clark electrode. The setup was described by Pouvreau et al. [35]. Anaerobic ferrous sulfate was added (1-10 $\mu \mathrm{l})$ with a gastight syringe after addition of ferritin. The volume of the cell was $2 \mathrm{ml}$. For the experiments in the presence of catalase, $200 \mu \mathrm{l}$ of a $3 \mathrm{mg} \mathrm{ml}^{-1}$ stock solution of catalase was added to the cell prior to the addition of an anaerobic solution of ferrous sulfate.

\section{Results}

Iron oxidation studies

Apoferritin was loaded with 0-2,000 $\mathrm{Fe}^{2+}$ per ferritin (PfFtn can maximally accumulate about $2,700 \mathrm{Fe}^{2+}$ per ferritin [31]) and samples were incubated at room temperature aerobically at least for $3 \mathrm{~h}$ and then overnight at $4{ }^{\circ} \mathrm{C}$. The extinction coefficient at $315 \mathrm{~nm}$ was found to be constant over the full range of iron loading: $\varepsilon_{315}=2.5 \mathrm{mM}^{-1} \mathrm{~cm}^{-1}$ (Fig. 2).

To determine the effect of background iron oxidation (i.e., not catalyzed by ferritin) in the initial-rate measurements, the specific activity of apoferritin and the background activity were measured and compared for a wide range of $\mathrm{Fe}^{2+}$ concentrations. The results indicate that the background oxidation of iron by dissolved dioxygen is negligible for an $\mathrm{Fe}^{2+}$ concentration below $1 \mathrm{mM}$, and with $0.3 \mu \mathrm{M}$ ferritin no precipitation of $\mathrm{Fe}^{2+}$ is observed. For an $\mathrm{Fe}^{2+}$ concentration between 1 and $3 \mathrm{mM}$, some precipitation of $\mathrm{Fe}^{3+}$ develops during the ferritin assay on a time scale of minutes, and at an $\mathrm{Fe}^{2+}$ concentration higher than $3 \mathrm{mM}$ the background oxidation is considerable and precipitation of iron even in the presence of ferritin is fast. The contribution of this background oxidation to the absorption at $315 \mathrm{~nm}$ typically increases exponentially up to saturation of the photomultiplier (Fig. S1a). Therefore, measurements at an $\mathrm{Fe}^{2+}$ concentration higher than $3 \mathrm{mM}$ are 

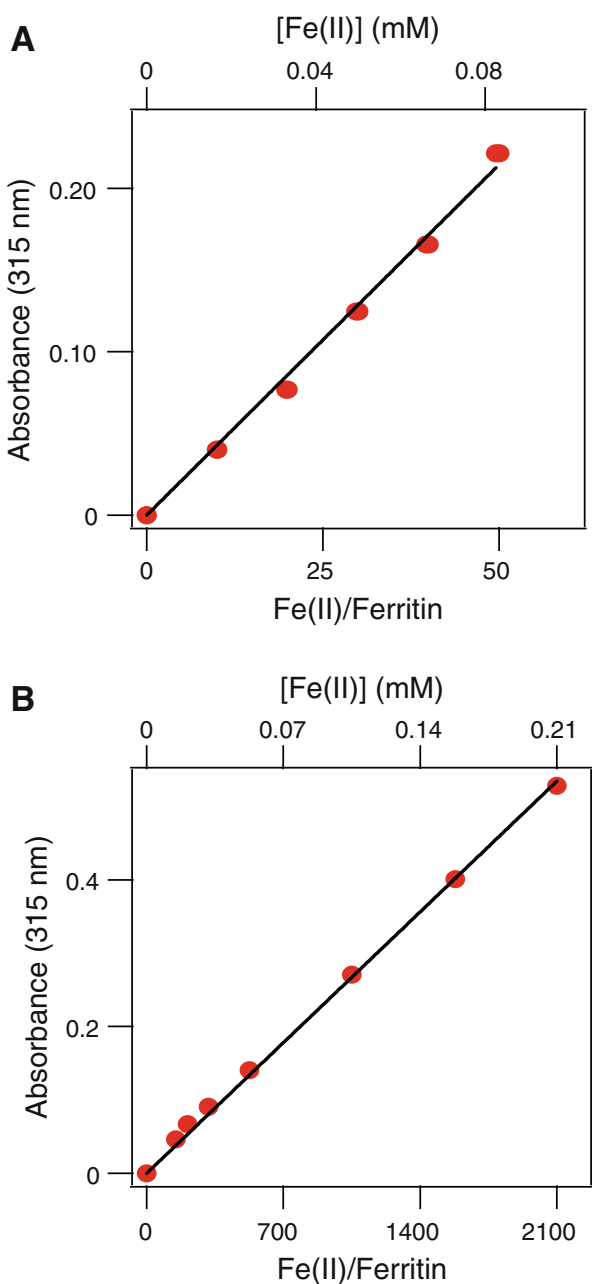

Fig. 2 Determination of the molar extinction coefficient at $315 \mathrm{~nm}$ for $P$. furiosus ferritin as a function of iron loading. a Low-iron plot: $\mathrm{Fe}^{2+}$ to ferritin ratio in the range $0-50$. The protein concentration was $1.65 \mu \mathrm{M}$. b High-iron plot: $\mathrm{Fe}^{2+}$ to ferritin ratio in the range $0-2,000$. The protein concentration was $0.105 \mu \mathrm{M}$

considered not reliable and all subsequent experiments were done at an $\mathrm{Fe}^{2+}$ concentration lower than $1 \mathrm{mM}$. The specific activity of apoferritin for $\mathrm{Fe}^{2+}$ concentrations in the range $0.03-3 \mathrm{mM}\left(\mathrm{Fe}^{2+}\right.$ to ferritin ratio $\left.100-10,000\right)$ is shown in Fig. 3. As reported previously [31], an initial phase suggesting cooperativity was observed in the activity versus $\mathrm{Fe}^{2+}$ concentration plot (Fig. 3). The molecular nature of the cooperativity has not been established. No indication of zero-order kinetics is found up to $3 \mathrm{mM}$ ferrous ion. A fit to the Hill equation [13, 16] affords a Hill coefficient of $1.55 \pm 0.15$, suggesting positive cooperativity for $\mathrm{Fe}^{2+}$ to ferritin ratios less than about 300, whereas $K_{\mathrm{M}}$ and $V_{\max }$ cannot be determined.

To study the role of the FC in iron oxidation, apoferritin was aerobically preloaded with various $\mathrm{Fe}^{2+}$ to ferritin ratios in the range 0-900. Preloaded samples were incubated at room temperature for at least $3 \mathrm{~h}$ and then

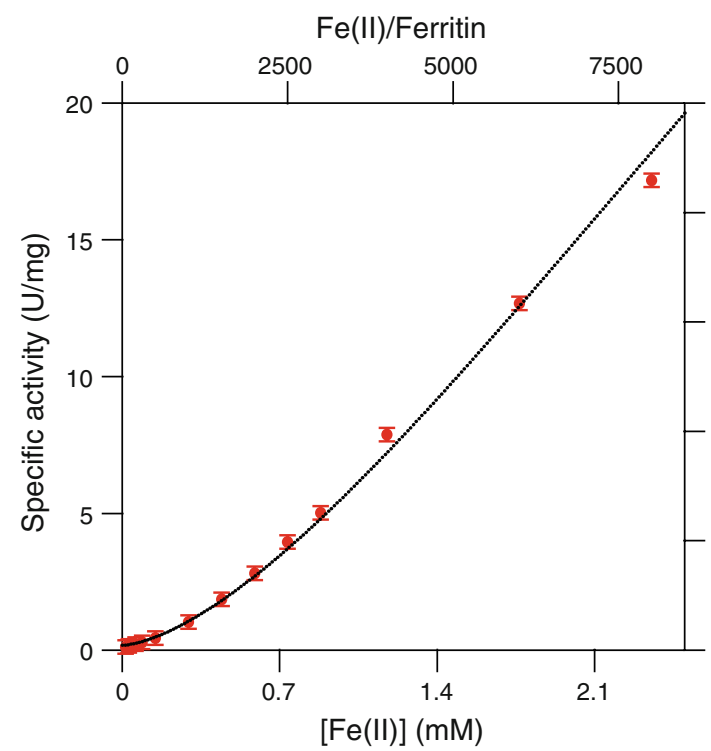

Fig. 3 Specific activity of $P$. furiosus apoferritin as a function of initial $\mathrm{Fe}^{2+}$ concentration. The protein concentration was $0.296 \mu \mathrm{M}$

overnight at $4{ }^{\circ} \mathrm{C}$. Subsequently, a progress curve was measured spectroscopically at $315 \mathrm{~nm}$ after a further addition of $48 \mathrm{Fe}^{2+}$ per ferritin to the samples under air. As an example, the progress curves for apoferritin, a ten $\mathrm{Fe}^{2+}$ per ferritin preloaded sample, a $20 \mathrm{Fe}^{2+}$ per ferritin preloaded sample, and a $100 \mathrm{Fe}^{2+}$ per ferritin preloaded sample are shown in Fig. 4a.

The progress curves for apoferritin and for preloaded samples with more than $48 \mathrm{Fe}^{2+}$ per ferritin showed a single exponential phase, whereas those for samples preloaded with 4,10 , and $20 \mathrm{Fe}^{2+}$ per ferritin showed two independent phases, a fast phase and a slow phase (Fig. 4a). The data were fitted to a double-exponential curve:

$A(t)=-m \exp \left(\frac{-t}{T_{1}}\right)-n \exp \left(\frac{-t}{T_{2}}\right)+A_{\infty}$,

in which $T_{1}$ and $T_{2}$ are time constants of the first and the second exponential, respectively. The complete set of progress curves was globally fitted with single values for $T_{1}$ and for $T_{2}$. It was observed that the preexponential factor $m$ decreases from a maximum for apoferritin to zero for samples preloaded with $\mathrm{Fe}^{2+}$ to ferritin ratios of more than about 48, whereas the factor $n$ increases from zero for apoferritin to a maximum for samples preloaded with $\mathrm{Fe}^{2+}$ to ferritin ratios of more than about 48 . The decrease in the fast phase and the increase in the slow phase are proportional to the number of FCs that were filled by aerobic preloading of apoferritin. The specific activity for the addition of $48 \mathrm{Fe}^{2+}$ to samples preloaded with $\mathrm{Fe}^{2+}$ to ferritin ratios greater than 48 is constant within experimental error (i.e., the specific activity is independent of the 

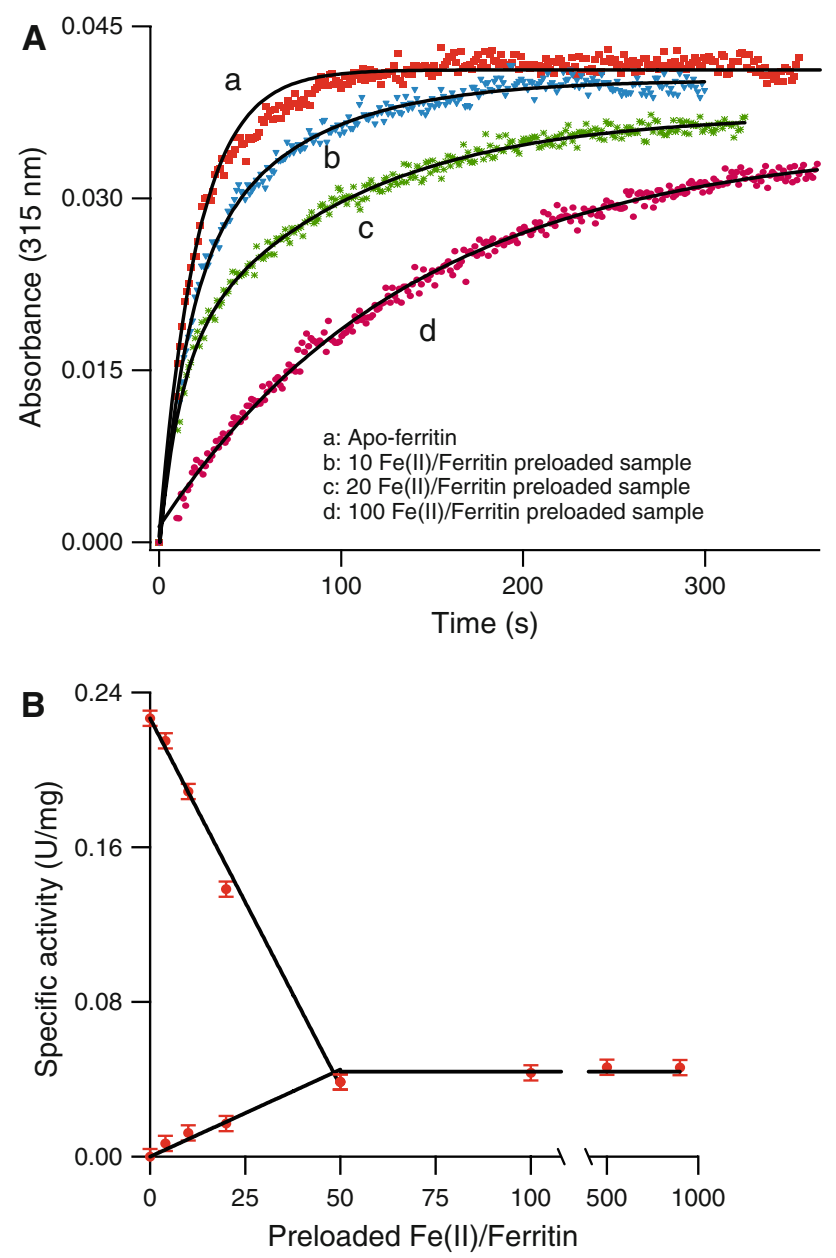

Fig. 4 Comparison of the specific iron-oxidation activity of $P$. furiosus apoferritin with that of aerobically $\mathrm{Fe}^{2+}$-preloaded ferritin. The initial substrate concentration in all cases was $48 \mathrm{Fe}^{2+}$ per ferritin. a Progress curves for apoferritin, a ten $\mathrm{Fe}^{2+}$ per ferritin preloaded sample, a $20 \mathrm{Fe}^{2+}$ per ferritin preloaded sample, and a 100 $\mathrm{Fe}^{2+}$ per ferritin preloaded sample at $315 \mathrm{~nm}$. The solid lines represent single-exponential or double-exponential fits. b Deconvolution into two processes of the specific activity versus the amount of $\mathrm{Fe}^{2+}$ that was preloaded aerobically to apoferritin: a process with high specific activity that decreases from apoferritin to $48 \mathrm{Fe}^{2+}$ per ferritin preloaded sample and a process with low specific activity that develops from zero to a maximum for $48 \mathrm{Fe}^{2+}$ per ferritin preloaded sample and that remains constant for preloaded samples with $\mathrm{Fe}^{2+}$ to ferritin ratios higher than 48 . The protein concentration was $0.33 \mu \mathrm{M}$

Table 1 Comparison of the specific activity of ferritin samples of different preloading

\begin{tabular}{ll}
\hline $\begin{array}{l}\text { Preloaded sample } \\
\text { (Fe/ferritin) }\end{array}$ & $\begin{array}{l}\text { Specific activity } \\
\left(\mathrm{U} \mathrm{mg}^{-1}\right)\end{array}$ \\
\hline 100 & $0.10 \pm 0.016$ \\
300 & $0.11 \pm 0.005$ \\
500 & $0.11 \pm 0.018$ \\
\hline
\end{tabular}

$100 \mathrm{Fe}^{2+}$ were added to different preloaded samples. The ferritin concentration was $0.24 \mu \mathrm{M}$
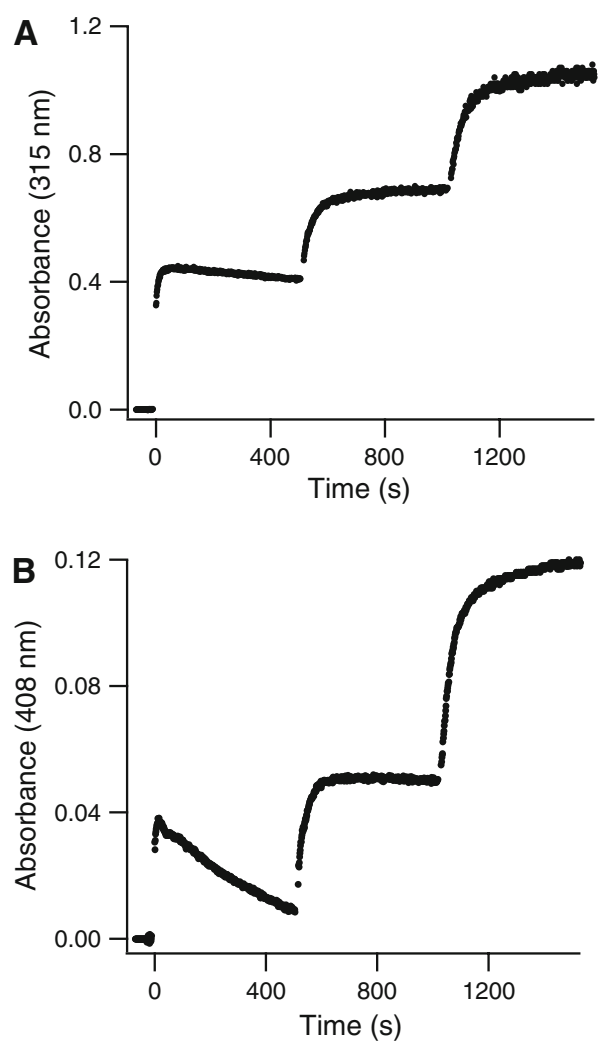

Fig. 5 Wavelength dependence of progress curves for iron oxidation by $P$. furiosus ferritin. Progress curves of apoferritin at a $315 \mathrm{~nm}$ and b $408 \mathrm{~nm} . \mathrm{Fe}^{2+}$ was added in three consecutive steps, $48 \mathrm{Fe}^{2+}$ per ferritin in each step. The protein concentration was $3.3 \mu \mathrm{M}$

core size). Also, when $100 \mathrm{Fe}^{2+}$ are added to samples preloaded with 100,300 , and $500 \mathrm{Fe}^{2+}$ per ferritin, the specific activity is similar for all preloaded samples: $0.10 \pm 0.02 \mathrm{U} \mathrm{mg}^{-1}$ (Table 1).

Progress curves were measured spectroscopically at several wavelengths for three sequential additions of aliquots of an anaerobic solution of ferrous sulfate to apoferritin, each addition corresponding to $48 \mathrm{Fe}^{2+}$ per ferritin. The patterns monitored at 315 and $408 \mathrm{~nm}$ are shown in Fig. 5.

The progress curve at $315 \mathrm{~nm}$ shows that the first 48 $\mathrm{Fe}^{2+}$ per ferritin are kinetically different from any equal amounts of iron added later. For the first addition the absorbance at $408 \mathrm{~nm}$ initially increases but then falls back to zero within $10 \mathrm{~min}$; however, for any subsequent addition of the same amount of iron the absorbance increases gradually and levels off upon substrate depletion.

\section{Oxygen-consumption studies}

The role of the FC in the iron-oxidation activity can also be studied by monitoring the second in vitro reactant: molecular oxygen. Aliquots of an anaerobic solution of ferrous sulfate were added to an aerobic solution of 
apoferritin in six steps, each step corresponding to $48 \mathrm{Fe}^{2+}$ per ferritin. The dioxygen-consumption curve, measured amperometrically, is shown in Fig. 6.

A single-exponential curve could be fitted to each step (not shown), and the thus determined initial dioxygen uptake rates and dioxygen to $\mathrm{Fe}^{2+}$ ratios (consumed dioxygen over oxidized iron) are presented in Table 2.

In the absence of catalase, a stoichiometry of two irons per oxygen molecule is found for the first addition of 48 $\mathrm{Fe}^{2+}$ per ferritin to apoferritin, which is attributed to the reaction at the $\mathrm{FC}$ and suggests production of hydrogen peroxide as a byproduct of iron oxidation by ferritin (reaction 1) $[22,36]$. When $48 \mathrm{Fe}^{2+}$ per ferritin were added to apoferritin in the presence of catalase, the dioxygen to $\mathrm{Fe}^{2+}$ ratio decreased to $0.41 \pm 0.02$, and the initial

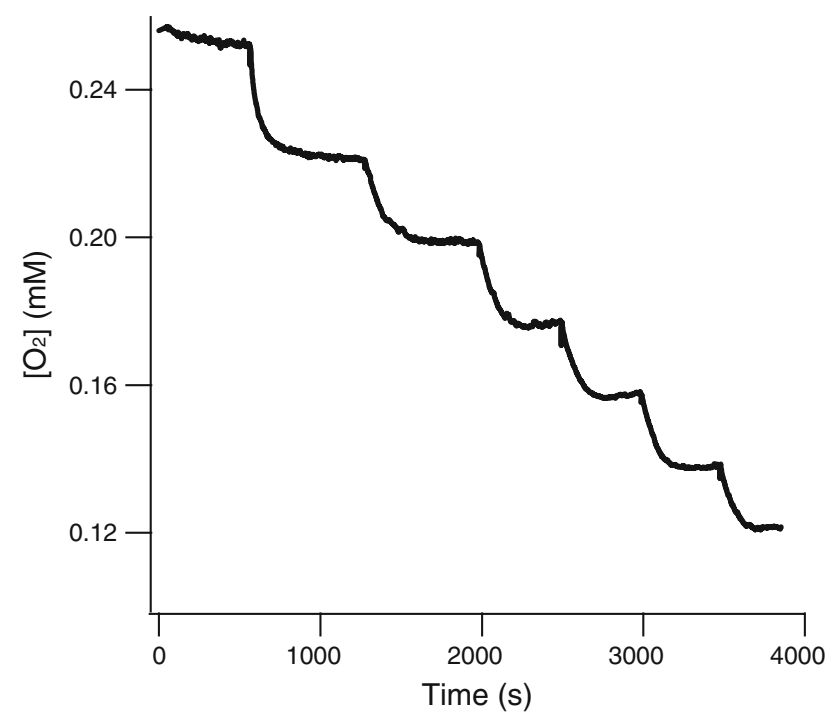

Fig. 6 Oxygen consumption by iron-oxidizing ferritin from $P$. furiosus. Aliquots of $5 \mu \mathrm{l}$ of an anaerobic solution of ferrous sulfate were added in six consecutive steps, $48 \mathrm{Fe}^{2+}$ per ferritin in each step. The protein concentration was $1.2 \mu \mathrm{M}$. The volume of the cell was $2 \mathrm{ml}$

Table 2 Dioxygen consumption upon repeated iron addition by $P y$ rococcus furiosus ferritin

\begin{tabular}{lll}
\hline Step & $\begin{array}{l}\text { Initial } \mathrm{O}_{2} \text { uptake } \\
\text { rate }\left(\mu \mathrm{M} \mathrm{s}^{-1}\right)\end{array}$ & $\mathrm{O}_{2} / \mathrm{Fe}^{2+}$ \\
\hline 1 & $0.63 \pm 0.02$ & $0.49 \pm 0.02$ \\
2 & $0.24 \pm 0.03$ & $0.42 \pm 0.02$ \\
3 & $0.17 \pm 0.02$ & $0.38 \pm 0.01$ \\
4 & $0.16 \pm 0.02$ & $0.35 \pm 0.02$ \\
5 & $0.16 \pm 0.01$ & $0.34 \pm 0.02$ \\
6 & $0.15 \pm 0.02$ & $0.28 \pm 0.02$ \\
\hline
\end{tabular}

The initial dioxygen uptake rate and the dioxygen to $\mathrm{Fe}^{2+}$ ratio are given for the addition of $\mathrm{Fe}^{2+}$ in six steps to apoferritin in the absence of catalase. Each step corresponds to $48 \mathrm{Fe}^{2+}$ per ferritin. The protein concentration was $1.2 \mu \mathrm{M}$ dioxygen uptake rate was $0.3 \pm 0.01 \mu \mathrm{M} \mathrm{s}^{-1}$, i.e., half of that when catalase was absent. A similar decrease in initial dioxygen uptake rate was observed for subsequent steps of adding $48 \mathrm{Fe}^{2+}$ per ferritin to ferritin in the presence of catalase. Upon the addition of catalase, $25 \%$ of the consumed dioxygen was recovered, a number that is similar to what has been reported for $\mathrm{H}$-subunit ferritin from bullfrog [37] but different from the observation that catalase can recover $100 \%$ of dioxygen for horse spleen ferritin and human ferritin [22]. The decrease in stoichiometry and initial dioxygen uptake rate in the presence of catalase strongly suggests that hydrogen peroxide is a byproduct of iron mineralization by PfFtn.

In the absence of catalase, the initial dioxygen uptake rates and the dioxygen to $\mathrm{Fe}^{2+}$ ratios gradually decrease to $0.15 \pm 0.02 \mu \mathrm{M} \mathrm{s}^{-1}$ and 0.28 dioxygen per $\mathrm{Fe}^{2+}$, respectively, for the sixth step (Table 2). Because $\mathrm{Fe}^{2+}$ was added in subsequent additions with short time intervals, it is likely that some of the $\mathrm{Fe}^{2+}$ was oxidized by hydrogen peroxide that had been produced in previous steps. The decrease in stoichiometry from $1: 2$ dioxygen to $\mathrm{Fe}^{2+}$ to 1:3.5 dioxygen to $\mathrm{Fe}^{2+}$ can be explained as the result of reactions 1 and 2; considering that less than $50 \%$ of $\mathrm{Fe}^{2+}$ will be oxidized by hydrogen peroxide that is produced by previous steps, and more iron will be processed by PfFtn.

To prevent oxidation of $\mathrm{Fe}^{2+}$ by hydrogen peroxide, apoferritin was preloaded with 100,500 , and $900 \mathrm{Fe}^{2+}$ per ferritin under air and preloaded samples were incubated at room temperature for at least $3 \mathrm{~h}$ and subsequently overnight at $4{ }^{\circ} \mathrm{C}$ to provide ample time for the essentially complete disproportionation of the hydrogen peroxide prior to subsequent iron addition. Then, an aliquot of $48 \mathrm{Fe}^{2+}$ per ferritin was added to each sample and oxygen consumption was measured. The initial dioxygen uptake rates and the dioxygen to $\mathrm{Fe}^{2+}$ ratios are presented in Table 3 .

The results presented in Table 3 show that the initial dioxygen uptake rate of apoferritin is faster than that of preloaded samples, but the initial dioxygen uptake rates of all preloaded samples are identical within experimental error. Apparently, apoferritin does not regenerate its initial activity after the first addition of $48 \mathrm{Fe}^{2+}$ per ferritin. Whenever an aliquot of $48 \mathrm{Fe}^{2+}$ per ferritin is added after a sufficiently long time interval, the number of $\mathrm{Fe}^{2+}$ oxidized by one oxygen molecule is close to two: dioxygen to $\mathrm{Fe}^{2+}$ ratio $0.47 \pm 0.01$ (Table 3 ). That the initial oxygen uptake rate of all preloaded samples is constant within experimental error suggests that oxidation of $\mathrm{Fe}^{2+}$ is independent of the degree of preloading, i.e., independent of the core size.

To check for possible catalytic activity of the core, indicated by a stoichiometry of four $\mathrm{Fe}^{2+}$ oxidized per dioxygen consumed (as proposed in [22, 23]), an aliquot of $300 \mathrm{Fe}^{2+}$ per ferritin was added in one step to apoferritin and also to samples preloaded with 100,500 , and $900 \mathrm{Fe}^{2+}$ 
Table 3 Comparison of dioxygen consumption by P. furiosus apoferritin and by iron-preloaded ferritin

\begin{tabular}{|c|c|c|c|}
\hline \multirow[t]{2}{*}{ Sample } & \multirow{2}{*}{$\begin{array}{l}\text { Initial } \mathrm{O}_{2} \text { uptake rate for } \\
48 \mathrm{Fe}^{2+} / \text { ferritin }\left(\mu \mathrm{M} \mathrm{s}^{-1}\right)\end{array}$} & \multicolumn{2}{|l|}{$\mathrm{O}_{2} / \mathrm{Fe}^{2+}$} \\
\hline & & $48 \mathrm{Fe}^{2+} /$ ferritin & $300 \mathrm{Fe}^{2+} /$ ferritin \\
\hline Apoferritin & $1.10 \pm 0.04$ & $0.48 \pm 0.01$ & $0.34 \pm 0.02$ \\
\hline Preloaded with $100 \mathrm{Fe}^{2+} /$ ferritin & $0.60 \pm 0.04$ & $0.47 \pm 0.02$ & $0.33 \pm 0.02$ \\
\hline Preloaded with $500 \mathrm{Fe}^{2+} /$ ferritin & $0.62 \pm 0.05$ & $0.46 \pm 0.02$ & $0.33 \pm 0.01$ \\
\hline Preloaded with $900 \mathrm{Fe}^{2+} /$ ferritin & $0.56 \pm 0.05$ & $0.46 \pm 0.03$ & $0.34 \pm 0.02$ \\
\hline
\end{tabular}

The initial dioxygen uptake rate and dioxygen to $\mathrm{Fe}^{2+}$ ratios for apoferritin and for samples aerobically preloaded with 100,500 , and $900 \mathrm{Fe}^{2+}$ per ferritin were measured when 48 or $300 \mathrm{Fe}^{2+}$ per ferritin were added. The protein concentration for addition of $48 \mathrm{Fe}^{2+}$ per ferritin was $1.65 \mu \mathrm{M}$ and for addition of $300 \mathrm{Fe}^{2+}$ per ferritin was $0.825 \mu \mathrm{M}$

per ferritin. Preloaded samples were incubated at room temperature for at least $3 \mathrm{~h}$, followed by overnight incubation at $4{ }^{\circ} \mathrm{C}$. The amount of dioxygen consumed by each sample is given in Table 3. Apoferritin and preloaded samples consume the same amount of dioxygen per added iron. The dioxygen to $\mathrm{Fe}^{2+}$ ratios of all samples are approximately 0.33 .

\section{Discussion}

Ferritins have been believed to store iron by means of a "substrate mechanism" in which $\mathrm{Fe}^{2+}$ ions are transiently bound to FCs, where they are oxidized, and from where they are subsequently transferred to the interior of the protein to become part of a growing mineral core [3, 13-20] (Fig. 7b). However, studies on the heme-containing EcBFR have led to the proposal that this substrate mechanism may not have general validity, and that some ferritins may operate by an alternative "catalytic mechanism" in which the FC acts as a stable, redox-active prosthetic group involved in electron transfer from a core that grows by self-catalysis [25] (Fig. 7c). Furthermore, the ferritin from the archaeon $P$. furiosus carries a FC that appears to be fully stable in reversible redox titrations [27]. We therefore decided to investigate the "catalytic mechanism" of iron uptake, proposed for EcBFR, as a working hypothesis for PfFtn to be tested in steady-state measurements of iron loading. In particular, we searched for significant differences in the characteristics of iron loading for the first $48 \mathrm{Fe}^{2+}$ into the empty FC sites of apoferritin as compared with the FC sites of ferritin samples preloaded with various $\mathrm{Fe}^{2+}$ to ferritin ratios. The latter were then hypothesized to be catalytically and spectroscopically different as they could potentially make use of a preformed and stable FC.

Since iron oxidation by ferritins is typically monitored by an increase in optical absorption at about $315 \mathrm{~nm}$, the extinction coefficient "at infinite time" (i.e., after completion of binding and oxidation) was measured for a wide range of iron loadings and was found to be constant over this range of iron concentration. In other words, formation of the FC in apoferritin cannot be discerned, on the basis of the final absorbance (i.e., after complete oxidation of all $\mathrm{Fe}^{2+}$ ions) at $315 \mathrm{~nm}$, from any additional core formation.

Ferrous iron is also oxidized at finite rates in aerobic aqueous solution in the absence of ferritin, and this nonbiological reaction represents an interfering background which becomes especially pronounced at higher iron concentrations (Fig. S1). For practical ferritin concentrations and ambient temperatures, it was found that iron oxidation by ferritin becomes unreliable at an $\mathrm{Fe}^{2+}$ concentration above $3 \mathrm{mM}$. This finding also implies a correction to our initial report on the specific activity of apoferritin over a wide range of $\mathrm{Fe}^{2+}$ concentration, 0-40 mM [31]. The previous conclusion that this activity is characterized by an apparent $K_{\mathrm{M}}$ of about $5 \mathrm{mM} \mathrm{Fe}^{2+}$ should be corrected to a $K_{\mathrm{M}}$ substantially larger than $2 \mathrm{mM}$ (with the implication that $K_{\mathrm{M}}$ may well be infinitely high).

The results of UV-vis spectroscopy rate measurements at $315 \mathrm{~nm}$ suggest that the first addition of $48 \mathrm{Fe}^{2+}$ per ferritin is kinetically different from subsequent additions of the same amount of iron. It appears that oxidation of the first $48 \mathrm{Fe}^{2+}$ per ferritin added to apoferritin occurs in the FC with a fast rate. As the number of FCs filled by preloading the apoferritin increases, the specific activity decreases, suggesting that fewer ferrous ions can be oxidized directly in the FCs and oxidation continues by a second mechanism which has a considerably lower specific activity and which becomes dominant when all the FCs are filled, i.e., in samples preloaded with $48 \mathrm{Fe}^{2+}$ per ferritin. The specific activity of the second reaction is independent of the core size. These findings appear to be inconsistent with a "substrate mechanism" in which all iron undergoes the same fate of passing through the FC, while restoring the FC activity to its initial state after each cycle. The data, in particular those in Fig. 4, would be consistent with a rapid synthesis of the FC (the fast phase) followed by a process in which incoming $\mathrm{Fe}^{2+}$ is catalytically oxidized by the FC to become incorporated in the core, the overall process being observed as the slow phase. 

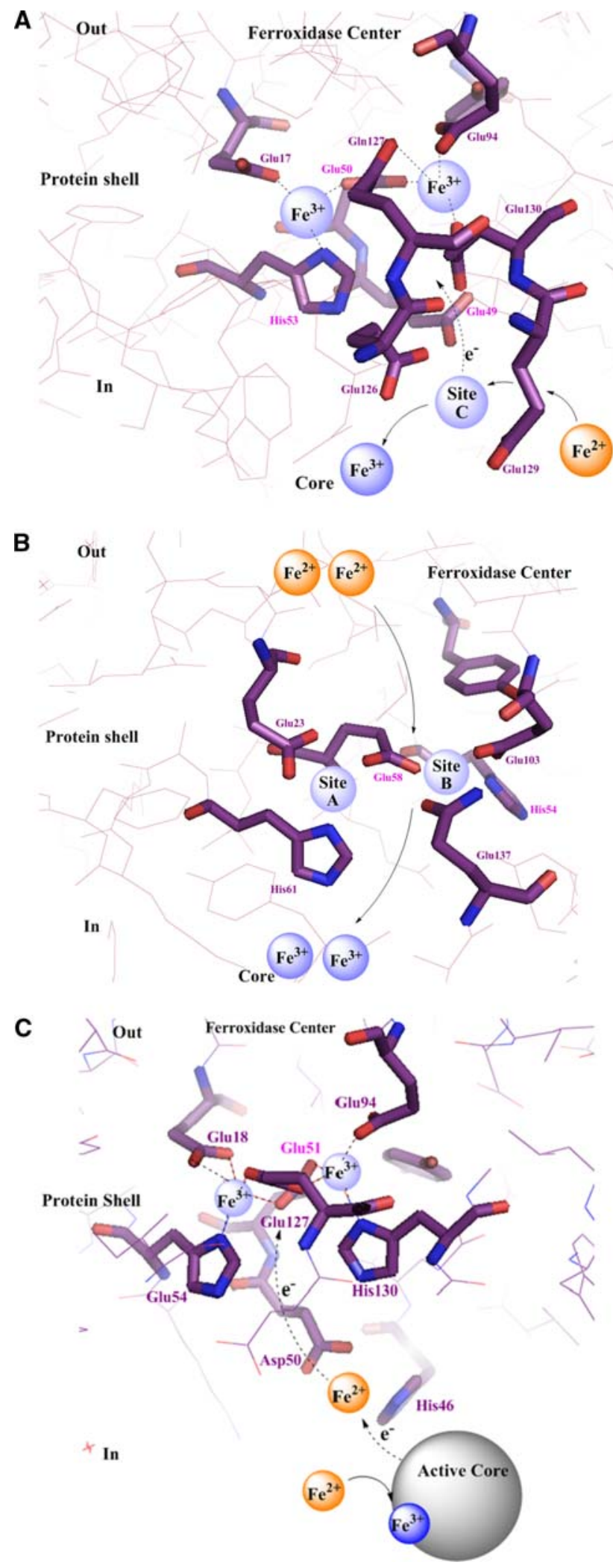

Iron oxidation rate measurements at $408 \mathrm{~nm}$ suggest that the first addition of $48 \mathrm{Fe}^{2+}$ per ferritin is spectrally different from any further addition of the same amount of
4 Fig. 7 Three models proposed for iron mineralization by ferritins. a Catalysis by the ferroxidase center proposed for the $P$. furiosus ferritin (PDB 2jd7). Ferrous ions are oxidized in binding sites near the ferroxidase center, e.g., site $\mathrm{C}$, through electron transfer to a stable ferroxidase center and are then released to the cavity to form a core. b Catalysis via a substrate site illustrated for bullfrog $M$ ferritin (PDB1mfr). Ferrous ions are oxidized in the ferroxidase center and are then released to the cavity to form a core. c Catalysis by the core proposed for Escherichia coli bacterioferritin (PDB2htn). Ferrous ions are oxidized on the surface of an active core and electrons are transferred to an oxidant such as molecular oxygen through the ferroxidase center

iron. At $408 \mathrm{~nm}$, for the first addition the absorbance increases rapidly and then slowly decreases over $10 \mathrm{~min}$. A similar decrease in absorbance has been observed for EcFtnA at $370 \mathrm{~nm}$ [38]. The molecular basis for these observations is not known but may well be a temporal rearrangement in the $\mathrm{FC}$ and/or in the $\mathrm{C}$ site.

Oxygen-consumption measurements in the absence of catalase suggest that the initial dioxygen uptake rate for the second addition of $48 \mathrm{Fe}^{2+}$ per ferritin is lower than that for the first addition, both after a short time interval and after overnight incubation of the ferritin aerobically preloaded with $100 \mathrm{Fe}^{2+}$ per ferritin. We conclude that, whereas it has been suggested that the FCs of a number of ferritin proteins such as human $\mathrm{H}$ chain ferritin, horse spleen ferritin, and mouse $\mathrm{H}$ chain ferritin can partially regenerate their activities [22, 23], P. furiosus apoferritin is rather more similar to EcBFR [39] in that it cannot regenerate its activity exhibited with the first addition of 48 $\mathrm{Fe}^{2+}$ per ferritin. Addition of $48 \mathrm{Fe}^{2+}$ per ferritin to apoferritin in the presence of catalase suggests that hydrogen peroxide is a byproduct of iron deposition by ferritin and that in the absence of catalase the gradual decrease in stoichiometry is due to the oxidation of some of the iron by hydrogen peroxide.

Although the initial dioxygen uptake rate of apoferritin is higher than that of preloaded samples, both apoferritin and preloaded samples eventually consume the same amount of dioxygen per oxidized $\mathrm{Fe}^{2+}$. A stoichiometry of two irons per oxygen molecule is found, as has been reported for mammalian ferritins [22-25, 40] but which is different from the stoichiometry of three to four $\mathrm{Fe}^{2+}$ per dioxygen reported for EcFtnA [38]. Whereas the observed stoichiometry of two $\mathrm{Fe}^{2+}$ oxidized per dioxygen consumed by other groups has been interpreted in favor of a "substrate active site FC model," the results of the kinetic studies reported here suggest that the mechanism of the reaction changes from a fast oxidation in the $\mathrm{FC}$ to a different mechanism (see below) after the first $48 \mathrm{Fe}^{2+}$ per ferritin have been used to build the FCs. The fact that the stoichiometry does not change from apoferritin to preloaded samples when iron is added in aliquots of $48 \mathrm{Fe}^{2+}$ per ferritin implies that the stoichiometry of the second 
mechanism is the same as the stoichiometry of the oxidation of the first $48 \mathrm{Fe}^{2+}$ per ferritin in the FCs.

In previous studies a catalytic iron-oxidation activity of the core was proposed on the basis of the observation that the number of oxygen molecules consumed per $\mathrm{Fe}^{2+}$ oxidized gradually decreases on increasing the amount of iron added to apoferritin in one step [22, 23, 28]. If this decrease is caused by the catalytic activity of the core, it is expected that addition of $300 \mathrm{Fe}^{2+}$ per ferritin in one step to different preloaded samples with different core sizes would lead to different stoichiometries. However, within experimental error, the dioxygen to $\mathrm{Fe}^{2+}$ ratios for apoferritin and all preloaded samples are identical. The decrease in the dioxygen to $\mathrm{Fe}^{2+}$ ratio to 0.33 compared with the ratio of 0.5 for charging with only $48 \mathrm{Fe}^{2+}$ per ferritin may well be the result of the oxidation of $\mathrm{Fe}^{2+}$ by the hydrogen peroxide that is produced during the ferritin mineralization process. A stoichiometry of 1:4 dioxygen to $\mathrm{Fe}^{2+}$ may be expected if half of the irons are oxidized by ferritin and half by hydrogen peroxide. The observed stoichiometry of 1:3 dioxygen to $\mathrm{Fe}^{2+}$ suggests that less than $50 \%$ of the $\mathrm{Fe}^{2+}$ is oxidized by hydrogen peroxide at this loading. Similar "intermediate" stoichiometries have been reported for human $\mathrm{H}$ chain ferritin [23]. That the stoichiometry is identical for apoferritin and preloaded samples suggest that an iron-oxidation activity of the core, previously reported for ferritins from other sources, does not apply to PfFtn. This conclusion is in agreement with the invariant kinetics of iron oxidation observed when $100 \mathrm{Fe}^{2+}$ per ferritin were added to three different preloaded samples, i.e., samples aerobically preloaded with 100,300 , and $500 \mathrm{Fe}^{2+}$ per ferritin.

Altogether the results suggest that the FC in PfFtn acts as a stable cofactor site. The first $48 \mathrm{Fe}^{2+}$ per ferritin are oxidized in the FC but do not leave the center. Oxidation of subsequently added iron appears to occur by a different mechanism, namely, a catalytic reaction that has a stoichiometry similar to that of the oxidation of the first 48 $\mathrm{Fe}^{2+}$ per ferritin in the $\mathrm{FC}$, but that has a lower specific activity in comparison with the specific activity of the oxidation of iron in the FC. Since the stable FC in PfFtn has previously been found to exhibit relatively similar reduction potentials for the one-electron reduction of the all-ferric form to the mixed-valence form and then to the all-ferrous form (about +0.2 and $+0.05 \mathrm{~V}$ [27]), we propose that the dinuclear $\mathrm{Fe}^{3+}$ site in the $\mathrm{FC}$ accepts two subsequent electrons from transiently nearby located $\mathrm{Fe}^{2+}$ ions (possibly at the $\mathrm{C}$ site; Fig. 7a) and oxidizes them to $\mathrm{Fe}^{3+}$. The resulting $\mathrm{Fe}^{3+}$ ions are then released to the cavity to form a core. To complete the cycle, electrons are transferred by the $\mathrm{Fe}^{3+}$ in the $\mathrm{FC}$ to an external oxidant, e.g., molecular oxygen.

The model of a catalytically active, stable prosthetic FC, proposed here, is schematically depicted in Fig. 7 together with the original substrate model and with the alternative catalytic-core model developed for bacterioferritin, including the recently discovered internal $\mathrm{Fe}^{2+}$ site proposed to be involved in electron transfer between the core and the FC [26]. As for other ferritins, the iron entry pathway for PfFtn is not known and needs further investigation. The threefold channels have been suggested as possible entry sites of $\mathrm{Fe}^{2+}$ into the ferritin cavity [41-43].

Whereas the data presented here on PfFtn appear to be incompatible with the catalytic-core model, they could still be understood in the frame of a drastically modified substrate model, namely, when one allows for the paradigm change that oxidized iron in the FC is not intrinsically labile, but only becomes mobile as the result of an event, such as a transient conformational change, induced by the binding and/or oxidation of newly incoming iron. Future experiments should help to decide the specific and perhaps general applicability of each of the alternatives outlined in Fig. 7.

Acknowledgments The PfFtn producing recombinant $E$. coli strain was kindly provided by J. Tatur. This work was supported by the Netherlands Research School Combination, Catalysis (NRSC-C).

Open Access This article is distributed under the terms of the Creative Commons Attribution Noncommercial License which permits any noncommercial use, distribution, and reproduction in any medium, provided the original author(s) and source are credited.

\section{References}

1. Rucker P, Torti FM, Torti SV (1996) J Biol Chem 271:3335233357

2. Laulhere JP, Lescure AM, Briat JF (1988) J Biol Chem 263:10289-10294

3. Liu X, Theil EC (2005) Acc Chem Res 38:167-175

4. Lewin A, Moore GR, Le Brun NE (2005) Dalton Trans 35973610

5. Ferreira C, Bucchini D, Martin ME, Levi S, Arosio P, Grandchamp B, Beaumont C (2000) J Biol Chem 275:3021-3024

6. Harrison PM, Arosio P (1996) Biochim Biophys Acta 1275:161-203

7. Tussaint L, Bertrand L, Hue L, Crichton RR, Declercq JP (2007) J Mol Biol 365:440-452

8. Ha Y, Shi D, Small GW, Theil EC, Allewell NM (1999) J Biol Inorg Chem 4:243-256

9. Tatur J, Hagen WR, Matias PM (2007) J Biol Inorg Chem $12: 615-630$

10. Johnson E, Cascio D, Sawaya MR, Gingery M, Schröder I (2005) Structure 13:637-648

11. Stillman TJ, Hempstead PD, Artymiuk PJ, Andrews SC, Hudson AJ, Treffry A, Guest JR, Harrison PM (2001) J Mol Biol 307:587-603

12. Treffry A, Zhao Z, Quail MA, Guest JR, Harrison PM (1998) J Biol Inorg Chem 3:682-688

13. Liu X, Theil EC (2004) Proc Natl Acad Sci USA 101:8557-8562

14. Theil EC, Takagi H, Small GW, He L, Tipton AR, Danger D (2000) Inorg Chim Acta 297:242-251 
15. Waldo GS, Ling J, Sanders-Loehr J, Theil EC (1993) Science 259:796-798

16. Schwartz JK, Liu XS, Tosha T, Theil EC, Solomon EI (2008) J Am Chem Soc 130:9441-9450

17. Tosha T, Hasan MR, Theil EC (2008) Proc Natl Acad Sci USA 105:18182-18187

18. Hwang J, Krebs C, Huynh BH, Edmondson DE, Theil EC, Penner-Hahn JE (1993) Science 287:122-125

19. Jameson GNL, Jin W, Krebs C, Perreira AS, Tavares P, Liu X, Theil EC, Huynh BH (2002) Biochemistry 41:13435-13443

20. Zhao G, Su M, Chasteen ND (2005) J Mol Biol 352:467-477

21. Bou-Abdallah F, Santambrogio P, Levi S, Arosio P, Chasteen ND (2005) J Mol Biol 347:543-554

22. Yang X, Chen-Barrett Y, Arosio P, Chasteen ND (1998) Biochemistry 37:9743-9750

23. Zhao G, Bou-Abdallah F, Arosio P, Levi S, Janus-Chandler C, Chasteen ND (2003) Biochemistry 42:3142-3150

24. Kolberg M, Strand KR, Graff P, Andersson KK (2004) Biochim Biophys Acta 1699:1-34

25. Baaghil S, Lewin A, Moore GR, Le Brun NE (2003) Biochemistry 42:14047-14056

26. Crow A, Lawson TL, Lewin A, Moore GR, Le Brun NE (2009) J Am Chem Soc 131:6808-6813

27. Tatur J, Hagen WR (2005) FEBS Lett 579:4729-4732

28. Xu B, Chasteen ND (1991) J Biol Chem 266:19965-19970

29. Chasteen ND, Harrison PM (1999) J Struct Biol 126:182-194
30. Proulx-Curry PM, Chasteen ND (1995) Coord Chem Rev 144:347-368

31. Tatur J, Hagedoorn PL, Overeijnder ML, Hagen WR (2006) Extremophiles 10:139-148

32. Bauminger ER, Harrison PM, Hechel D, Nowik I, Treffry A (1991) Biochim Biophys Acta 1118:48-58

33. Dawson MC, Elliott DC, Elliott WH, Jones KM (1986) Data for biochemical research, 3rd edn. Clarendon Press, Oxford

34. Matias PM, Tatur J, Carrondo MA, Hagen WR (2005) Acta Crystallogr 61:503-506

35. Pouvreau LAM, Strampraad MJF, Van Berloo S, Kattenberg JH, de Vries S (2008) Methods Enzymol 436:97-112

36. Bou-Abdallah F, Lewin AC, Le Brun NE, Moore GR, Chasteen ND (2002) J Biol Chem 277:37064-37069

37. Waldo GS, Theil EC (1993) Biochemistry 32:13262-13269

38. Treffry A, Zhao Z, Quail MA, Guest JR, Harrison PM (1998) FEBS Lett 432:213-218

39. Yang X, Le Brun NE, Thomson AJ, Moore GR, Chasteen ND (2000) Biochemistry 39:4915-4923

40. Sun S, Chasteen ND (1992) J Biol Chem 267:25160-25166

41. Bou-Abdallah F, Zhao G, Biasiotto G, Poli M, Arosio P, Chasteen ND (2008) J Am Chem Soc 130:17801-17811

42. Yablonski MJ, Theil EC (1992) Biochemistry 31:9680-9684

43. Treffry A, Bauminger ER, Hechel D, Hodson NW, Nowik I, Yewdall SJ, Harrison PM (1993) Biochem J 296:721-728 